\title{
A COMERCIALIZAÇÃO DE UVAS FINAS NA REGIÃO DE JALES - SP ${ }^{1}$
}

\author{
SÍLVIA MARIAALMEIDA LIMA COSTA², MARCOS ROBERTO LACERDA GOMES ${ }^{3}$, \\ MARIAAPARECIDAANSELMO TARSITANO ${ }^{4}$
}

RESUMO - A produção de uvas finas para mesa destaca-se entre as principais atividades econômicas da região noroeste do Estado de São Paulo, Brasil. Entretanto, os produtores comumente apontam os problemas relativos à comercialização da fruta como um dos mais importantes obstáculos interpostos ao desenvolvimento da fruticultura regional. Este trabalho analisa as transações entre produtores e agentes de comercialização da fruta, discutindo as estruturas de governança presentes e as razões que explicam a exposição dos produtores a comportamentos oportunísticos associados aos distribuidores. Conclui-se que produtores que desenvolvem sistemas produtivos mais especializados, ofertadores de frutas de melhor qualidade, são atendidos por agentes de intermediação também especializados e, portanto, estão menos expostos a comportamentos oportunísticos. Nestes casos, a relação entre os agentes -torna-se mais efetiva e sistemática, e a estrutura de governança transita de coordenação via mercado para formas híbridas.

Termos para indexação: uva, economia dos custos de transação, comercialização.

\section{COMERCIALIZATION OF FINE GRAPES IN THE REGION OF JALES,STATE OF SÃO PAULO}

ABSTRACT - The production of fine grapes stands out among the most important economical activities in the Northwest region of the State of São Paulo, Brazil. However, this area's farmers commonly point out problems referring to the commercialization of the fruit as one of the most important obstacles interposed to the development of the regional horticulture. This work analyzes the transactions between producers and the agents of the fruit commercialization, arguing about the actual governance structures and the reasons which explain the producers exposition to opportunist behaviors associated to the delivers. It is concluded that producers who develop more specialized productive systems and offer better quality of fruits are attended by intermediary agents also specialized, and therefore they are less exposed to opportunist behaviors. In these cases the relationship between the agents becomes more effective and systematic, and the governance structures transits from market coordination through hybrid forms.

Index terms: grape, transaction economics cost, fruit commercialization.

\section{INTRODUÇÃO}

A uva é uma das frutas mais consumidas no mundo, seja na forma in natura, seja como suco. O consumo brasileiro de uvas de mesa tem apresentado tendência crescente; nos anos oitenta, perfazia uma média de $0,62 \mathrm{~kg}$ per capita, evoluindo para $2,18 \mathrm{~kg}$ nos anos noventa (Gonçalves et al., 1998) e 2,9 kg em 2002 (Sato, 2004).

Na região noroeste paulista, a viticultura tem apresentado grande importância na composição da produção e renda regional. Em 2005, a área sob exploração da uva na região de Jales foi de 1.091,4 ha distribuídos entre 951,2 ha para as variedades de uvas finas de mesa (com destaque para Itália, Rubi, Benitaka e Brasil) e 140,2 ha com uvas rústicas (destacando-se a variedade Niagara $)^{1}$.

A região despontou como importante pólo produtor de uvas para mesa nos anos 80 e 90, alcançando participação destacada no abastecimento nacional de uvas finas, o que permitiu que a produção fosse direcionada para períodos de entressafras de outras tradicionais regiões produtoras de uvas do Estado (junho-novembro), quando o produto potencialmente alcança melhores preços.

Entretanto, os problemas relativos à comercialização da fruta são comumente referidos como um dos mais importantes obstáculos interpostos ao desenvolvimento da fruticultura regional. Em especial, apresenta-se o fato de os produtores se mostrarem muito vulneráveis e temerosos quanto à possibilidade de se defrontarem, em suas relações comerciais, com frustrações de receitas decorrentes de inadimplência dos agentes compradores. Esse temor está relacionado a grandes calotes, muitos de grande monta, sofridos por parte dos produtores regionais em anos de boas produtividades. Nos últimos anos, esse problema deixou de ser relevante para parte dos produtores, que desenvolveram estratégias mais eficientes de comercialização².

Este trabalho tem como objetivo analisar as transações entre produtores e agentes de comercialização de uvas de mesa de Jales, região noroeste do Estado de São Paulo. Além de discutir os atributos transacionais existentes na coordenação da atividade de comercialização entre produtores e agentes de intermediação, procura-se também discutir as razões que justificam o grande temor manifestado por viticultores da região, de se defrontarem

1(Trabalho 056-07). Recebido em: 05-03-2007. Aceito para publicação em: 14-11-2007.

${ }^{2}$ Universidade Estadual Paulista, UNESP, Campus de Ilha Solteira. Av. Brasil Centro, 56, Ilha Solteira-SP. 15.385-000. Email:smalcost@agr.feis.unesp.br ${ }^{3}$ União das Faculdades dos Grandes Lagos, UNILAGO. R. Dr. Eduardo Nielsen, 960. Jd. N.Aeroporto, São José do Rio Preto, SP, 15.030-060. Email lacerda.adm@itelefonica.com.br.

${ }^{4}$ Universidade Estadual Paulista, UNESP, Câmpus de Ilha Solteira. Av. Brasil Centro, 56 Ilha Solteira-SP. 15.385-000. Email:maat@agr.feis.unesp.br 'Os dados são da Coordenadoria de Assistência Técnica Integral (CATI), regional de Jales-SP. 
com ameaças de não-pagamento de suas vendas pelos agentes de comercialização ${ }^{6}$.

Assim, pretende-se: a) discutir os canais de distribuição da uva produzida na região; b) detectar como se dá o relacionamento comercial entre produtor e agentes de comercialização e distribuição, identificando os principais problemas e entraves nessa relação, e c) identificar modos organizacionais que determinam as características das transações e das condições das instituições que operam no sistema.

\section{MATERIAL E MÉTODOS}

A região de Jales dista aproximadamente $600 \mathrm{~km}$ da Capital do Estado de São Paulo, abrangendo 22 municípios em uma área de cerca de 311 mil hectares. Representa o segundo maior pólo em importância na produção de uvas de mesa do Estado.

Para abordagem junto a produtores e agentes de comercialização, técnicos (atuantes no sistema oficial de extensão rural, Coordenadoria de Assistência Técnica) e outros representantes de atores coletivos foi aplicado um questionário baseado em entrevistas presenciais e semi-estruturadas.

O questionário aplicado aos produtores teve por meta captar aspectos referentes a: a) a composição das explorações agropecuárias com que trabalha; $b$ ) ao grau de satisfação com a produção de uvas de mesa; $c$ ) atributos qualitativos atribuídos e mensuráveis à produção própria e os da produção vinícola regional; $d$ ) canais de comercialização presentes regionalmente e explorados pelo produtor e que tipo de exigências impõem e/ ou lhes são estabelecidas pelos compradores; e) volume e freqüência de vendas; $f$ ) existência e participação em entidades de representação de classe, como associações, cooperativas e outros atores sociais

Como uma boa referência para padrões de qualidade a serem considerados pelo segmento produtivo de uvas de mesa, considera-se a norma de classificação para uvas de mesa elaborada pelo "Programa Brasileiro para a Melhoria dos Padrões Comerciais e Embalagens de Hortifrutigranjeiros", este decorrente dos trabalhos desenvolvidos no Centro de Qualidade em Horticultura (CQH) do Entreposto Terminal de São Paulo, CEAGESP $^{3}$

Essa central de abastecimento desempenha um importante papel na distribuição de produtos hortícolas produzidos no Brasil e em países do Mercosul. As normas, elaboradas para facilitar a linguagem da comercialização no mercado, definem características do produto, como: identidade, qualidade, acondicionamento, embalagem, rotulagem e apresentação do produto, tais como descritos em Gutierrez e Resende (2000).

Para os agentes de comercialização, a abordagem procurou identificar como se caracteriza a relação com produtores, quais os atributos técnicos considerados importantes na compra das frutas, quais exigências são impostas para os produtores e a quais exigências respondem, os custos de comercialização e para quais tipos de equipamentos varejistas de distribuição hortifrutigranjeira a produção é encaminhada.
A coleta de dados baseou-se em entrevistas presenciais e semi-estruturadas com uma amostra de 29 agentes atuantes em distintos segmentos da cadeia produtiva de uva de mesa regional. Deste universo, 19 são viticultores, dos quais quatro apresentam mais de 21 anos de experiência na atividade, 12 apresentam entre 10 e 20 anos de experiência na atividade e 3 produtores contam com até 10 anos de experiência com plantio de uva. Abordaramse ainda 5 engenheiros agrônomos: um atua em estabelecimento comercial de revenda de insumos para fruticultores; três atuam na prestação de serviços de assistência técnica e extensão rural (entre particular e oficial), e um, à época, trabalhava junto à prefeitura municipal de Jales. Abordaram-se também um presidente de cooperativa de fruticultores; três agentes de comercialização (responsáveis pela distribuição da fruta na região ou para permissionários do CEAGESP), e um presidente de instituição prestadora de serviços jurídicos aos fruticultores.

A Economia dos Custos de Transação (ECT) constitui-se em referencial interessante para o entendimento das relações que se estabelecem entre produtores e agentes de comercialização (distribuidores nos canais de comercialização).

Por transação, entende-se a transferência de bens e serviços por interfaces tecnologicamente distintas. Para Coase (1937), os custos de transação podem ser divididos entre os custos de coleta de informações e os custos de negociação e estabelecimento de um contrato. $\mathrm{O}$ pressuposto básico é que existem custos na utilização do sistema de preços, os quais requerem muitas vezes a condução de contratos intrafirmas. $\mathrm{O}$ segundo pressuposto é o de que as transações ocorrem em um ambiente institucional estruturado, e as instituições não são neutras, ou seja, interferem nos custos de transação. Outros dois pressupostos importantes da ECT são: oportunismo e racionalidade limitada. Racionalidade limitada refere-se ao comportamento que pretende ser racional, mas consegue sê-lo apenas de forma limitada, como define Williamson, citado por Zylbersztajn (1995). Disto decorre o conceito de incompletude contratual, pelo qual os contratos não conseguem prever as contingências que envolvem as transações. O oportunismo é um pressuposto que se reporta à ação dos indivíduos em busca do auto-interesse, podendo levá-los a agir de modo oportunístico (Zylbersztajn, 1995).

$\mathrm{O}$ ambiente institucional corresponde ao sistema de normas (restrições informais, regras formais e sistemas de controle) que afetam a posse ou transferência dos direitos de propriedade de bens. O termo "estrutura de governança" é também utilizado para definir o conjunto de regras formuladas pelas instituições, as quais governam determinada transação e são voltadas para redução dos custos de transação (Farina et al., 1997).

Os atributos fundamentais das transações são freqüência, incerteza e especificidade dos ativos; a configuração desses atributos é importante na definição da estrutura de governança ideal para regular a transação (Williamson,1985). Dentre estes atributos, a freqüência diz respeito a quão recorrentes acontecem as transações em um período de tempo; a incerteza refere-se à ocorrência de acontecimentos imponderáveis, não previstos exante a elaboração dos acordos de troca. Relaciona-se ao

${ }^{3}$ CEAGESP: Companhia de Entrepostos e Armazéns Gerais de São Paulo. Uma descrição dos trabalhos e instituições envolvidas na elaboração das Normas de Classificação de Hortigranjeiros encontra-se em CEAGESP: Companhia de Entrepostos e Armazes
Almeida (2000) e em Gutierrez e Resende (2000)

Rev. Bras. Frutic., Jaboticabal - SP, v. 30, n. 1, p. 127-132, Março 2008 
pressuposto comportamental racionalidade limitada dos agentes econômicos, dada a incapacidade destes em antecipar todos os acontecimentos futuros intervenientes da transação.

O terceiro atributo transacional é a especificidade dos ativos, entendida como sendo a magnitude do valor dos ativos relevantes associados a determinada transação. Williamson (1991) aponta seis principais tipos de especificidades de ativos: a) especificidade locacional: reporta-se à proximidade de firmas pertencentes à mesma cadeia produtiva, o que possibilita, por exemplo, a ocorrência de economias em custos de transporte e armazenagem; b) ativos físicos: as características físicas dos ativos determinam se os mesmos são mais ou menos exclusivos para determinados sistemas produtivos; c) ativos humanos: reporta-se ao conhecimento ou experiência acumulada ao longo do tempo que tornam específicas as competências dos recursos humanos para determinados sistemas produtivos; d) ativos dedicados: são os investimentos realizados com a expectativa de demanda para um agente em particular, sendo dedicados a este; e) especificidade de marca: refere-se aos valores intangíveis associados à marca de determinada empresa ou produto; f) especificidade temporal: ocorre quando o valor de uma transação depende fortemente do tempo em que a mesma se processa. Este é o caso de muitos produtos da agropecuária que se caracterizam por possuir elevada perecibilidade.

Assim, é a relevância dos atributos transacionais que determinará a estrutura de governança mais eficiente para regular as transações, isto é, que envolvam menores custos. As formas mais clássicas em que acontecem as transações, são agrupadas em três grupos representativos, quais sejam: transações via mercado, formas híbridas e hierarquia.

$\mathrm{Na}$ forma mercado, a transação é encerrada em um ponto no tempo, não havendo expectativa de acontecer recorrência no futuro. Na forma hierárquica, ocorre incorporação das relações para dentro dos domínios da firma. Entre essas formas extremas, ocorrem formas contratuais diversas comumente presentes na comercialização de frutas, verduras e legumes, como atestam Faulin e Azevedo (2003).

A forma analítica proposta por Williamson (1991), para se comparar às diferentes formas organizacionais, tem como variável principal a especificidade dos ativos (k); freqüência, incerteza e características do ambiente institucional são parâmetros de deslocamento das funções, representados por $\theta$. As funções que representam as formas organizacionais são mercado, $\mathrm{M}(\mathrm{K}$, $\theta)$; híbrida, $X(K, \theta)$, e hierárquica $(\mathrm{k}, \theta)$. A especificidade dos ativos é a característica que determina a mudança da coordenação via mercado para formas mais complexas de estruturas de governança.

A Figura 1 apresenta a relação entre custos de cada estrutura de governança e a especificidade dos ativos; na situação $\mathrm{K}_{1}$, os agentes são indiferentes entre as formas híbridas e de mercado. Em K2, os agentes são indiferentes entre as formas híbrida e hierárquica. Curva envelope, dada pela junção entre os trechos das curvas de custo de mercado, híbrida e hierárquica, representa a escolha ótima da forma organizacional para cada especificidade de ativos.

\section{RESULTADOS E DISCUSSÕES}

As especificidades identificadas dos ativos característicos da produção e comercialização de uvas finas para mesa são: baixa especificidade locacional, média especificidade de ativos físicos e humanos, e um caso de especificidade de marca.

A região noroeste do Estado de São Paulo apresenta condições edafoclimáticas especiais, as quais, adicionadas à técnica de condução de duas podas nas videiras, tornam possível programar as colheitas para colocação nos mercados em meses de entressafra das outras importantes regiões produtoras do Estado de São Paulo (agosto a novembro). Embora peculiar neste Estado, outras regiões produtivas do País, como os Estados de Pernambuco e o Estado do Paraná também apresentam características edafoclimáticas favoráveis e concorrem com a uva de Jales nos grandes entrepostos atacadistas, por isso a baixa especificidade locacional.

No caso de ativos físicos possuírem média especificidade, justifica-se por ser a videira cultura perene, possuindo horizonte de vida útil definida pelos sistemas produtivos regionais de $10 \mathrm{a}$ 12 anos, e demandando 7 anos para amortizar os investimentos realizados (TARSITANO, 2001). Ademais, alguns itens da composição dos gastos com investimentos destinados à atividade são de difícil reaproveitamento em outras atividades, tais como as despesas para formação do parreiral, que envolvem desde a aquisição dos porta-enxertos até a estrutura para a condução e proteção das plantas (postes, aramados e tela plástica suspensa sobre as videiras). Em geral, quando o produtor toma a decisão de encerrar as atividades produtivas com a cultura, ele ainda prossegue produzindo até o vencimento da vida útil da mesma.

Os ativos humanos utilizados nos sistemas produtivos regionais são considerados também de média especificidade, pois necessitam de mão-de-obra especialmente treinada para realizar as operações delicadas que compõem os tratos culturais da videira, como operações de desbrota, desbaste dos cachos (com a utilização de pente próprio); as operações de colheita e póscolheita; estas últimas devem ser realizadas com o mínimo manuseio para evitar danos físicos ou que acelerem a perecibilidade da fruta. Esta pesquisa permitiu verificar que a qualidade da uva produzida guarda uma associação positiva com a presença de recursos humanos altamente treinados para a condução daquelas operações, e que estes são tanto mais qualificados quanto maior o tempo de atividade no sistema produtivo. Na região, a condução de todos os tratos culturais associados à exploração da cultura é realizada com mão-de-obra familiar especializada.

Especificidade de marca: dentre as entrevistas efetuadas, um caso foi identificado que, como é desejável, atesta um diferencial positivo de qualidade da fruta comercializada pelo produtor. Neste caso, o produtor vende sua produção para permissionários do Entreposto Terminal Atacadista CEAGESP e, sistematicamente, recebe preços acima da média praticada no mercado.

As transações comerciais das uvas de mesa são recorrentes, com periodicidade semanal nos meses de safra (julho 
a novembro). A videira apresenta um ciclo produtivo em torno de 150 dias após a poda de formação, é bastante suscetível a doenças fúngicas, exigindo exaustivo programa de aplicações preventivas de defensivos, além de ser altamente perecível. Em geral, o transporte da fruta para distribuição nos mercados de destino é feito no mesmo dia em que se realiza a colheita. Esse conjunto de características imprime elevada especificidade temporal para a fruta.

A entrevista buscou captar dos produtores as principais fontes de incertezas com as quais se defrontam: a primeira é comum às demais explorações agrícolas, refere-se àquelas associadas às intempéries de origem climáticas e ocorrência de doenças e pragas; as demais fontes de incertezas estão associadas à comercialização e são, em ordem de importância: o comportamento dos preços, o receio de se defrontarem com compradores que se tornem inadimplentes (ocorrência de "calotes"), o receio de "perder a uva no pé", possibilidade que se consubstancia quando não são visitados pelos agentes de comercialização compradores.

Dos produtores entrevistados, a grande maioria utiliza como fonte de informação, para conhecimento do comportamento de mercado de uva, as conversas informais com vizinhos produtores, conjugadas a consultas sobre o preço praticado por agentes de comercialização atuantes no entreposto CEAGESP. Em apenas um caso, o produtor faz uso da Internet para o entendimento mais amplo daquele comportamento. A fonte de incerteza relacionada ao desempenho dos agentes de comercialização (corretores, comissionários ou atacadistas) que adquirem a fruta do produtor para distribuição nos entrepostos de abastecimento ou na rede de varejo, embora muito presente, hoje é percebida como menos importante do que no passado recente e será discutida adiante.

Quando solicitados para apontar as características que definem bons padrões de qualidade para uvas finas de mesas, a maioria dos produtores indicou, por ordem de importância: o brix (açúcar), a coloração uniforme das frutas e o tamanho dos bagos e cachos. Entretanto, os produtores não fizeram referência explícita às normas de classificação de uva fina elaborada pelo CEAGESP, com exceção do produtor que desenvolveu marca própria.

\section{Estruturas de governança}

De maneira geral, as estruturas de governança utilizadas pelos produtores de uvas de mesa da região são mercado e estruturas híbridas. A estrutura mercado predomina amplamente sobre a estrutura híbrida, esta consubstanciada pela organização da comercialização da produção através de uma cooperativa de produtores a qual, entretanto, não tem ainda desempenhado importante função na coordenação das atividades produtivas e de comercialização, segundo os próprios produtores.

Os mercados mais freqüentes para os quais são destinadas as uvas de mesa produzidas na região de Jales, são os entrepostos de abastecimento CEASAs das grandes cidades e a central terminal CEAGESP São Paulo. Nestes entrepostos, estão os atacadistas que intermediam a distribuição para a rede de varejo.

As vendas para estes mercados terminais podem ocorrer sob a forma de vendas diretas pelo produtor, que toma para si a função de transportar para esses mercados, arcando com os custos de frete, descarga, etc. Essa é uma forma menos comum atualmente, tanto porque o principal mercado, a CEAGESP, dista cerca de $600 \mathrm{~km}$ da região de Jales, quanto porque, do ponto de vista do produtor, assumir a função de transporte conflita com o tempo do agricultor, já bastante concorrido na dedicação aos sistemas produtivos da propriedade. Além disso, os lotes de produtos disponibilizados para comercialização não apresentam escala que justifique esforços individuais para transporte, pois o produtor, ao realizar a poda de frutificação, o faz de maneira escalonada para que possa realizar a operação de colheita também de forma escalonada.

Outra forma de comercialização mais comum é a venda para um agente comissionário ou corretor representante das empresas atacadistas; estes são conhecidos popularmente na região como "mateiros". Na realidade, este agente de comercialização pode ser classificado em duas categorias distintas: uma primeira que chamamos de especializados; buscam a coordenação das atividades de compra, de logística e fazem o trabalho de desenvolvimento de produtores para serem fornecedores, com vistas a coordenar o fluxo de distribuição de produtos para os equipamentos de varejo regionais mais exigentes ou para as centrais de abastecimento.

Em alguns casos, a atuação daqueles agentes é coordenada por relações contratuais entre estes e as empresas distribuidoras que atuam nos entrepostos atacadistas. Este trabalho envolve o estabelecimento de vínculos mais duradouros e efetivos com os produtores. Esperam que estes lhes forneçam frutas de qualidade, não necessariamente expressas pelo padrão de classificação oficial adotado pela CEAGESP, mas que apresentem boa coloração, doces e com cachos e bagas uniformes. Procuram ter controle sobre a qualidade da produção regional, fazem visitas regulares aos produtores antes dos meses de colheita para se informarem sobre as condições de desenvolvimento da cultura e possível qualidade na origem, com vistas a inferir em que medida os procedimentos e as conduções resultarão em frutas alinhadas com a qualidade requerida pelos equipamentos da grande distribuição, as quais retransmitem o padrão de qualidade requerido pelo varejo. Esse é o caso em que se observa um avanço nas relações entre produtores e distribuidores, constituindo-se em forma híbrida de relacionamento na coordenação da relação entre os mesmos; neste caso, as relações possuem salvaguardas de ordem reputacional, tal como discutido por Faulin e Azevedo (2003) e por Belik (2005).

As formas de pagamento da fruta na região são a de preço preestabelecido (combinado) ou pagamento por consignação, na qual o produtor não tem conhecimento do preço que receberá quando da entrega da fruta. O viticultor recebe $a$ posteriori o preço líquido, após descontos referentes aos custos médios de comercialização com transporte, descarregamento, comissão do atacadista ( $15 \%$ do valor da venda de cada lote) e com a contribuição especial da seguridade social rural, de 2,3\% sobre o valor da produção.

A outra categoria de intermediários são os mateiros, neste 
caso denominados pouco especializados. São menos exigentes em qualidade, podem ser distribuidores para equipamentos varejistas regionais ou centros de consumo mais distantes. Realizam transações com freqüência de relacionamento variável com os produtores, podem transportar as frutas em caixas abertas, e neste caso, são também chamados caixoteiros. Nesta categoria, inserem-se também os agentes de comercialização autores das inadimplências de pagamentos de compras de lotes de frutas adquiridos junto a produtores. Calotes de grande monta que ocorreram no final dos anos noventa, deixando desguarnecidos um número significativo de produtores, marcaram a história do negócio vitícola regional; atualmente ainda ocorrem, porém em menor escala e de forma esporádica.

Das entrevistas realizadas junto a produtores e distribuidores, foi possível inferir que os produtores regionais estão sujeitos a se defrontarem com dois tipos de situações aqui qualificadas como de comportamento oportunístico ex-ante e comportamento oportunístico induzido (ex-post).

No caso do comportamento oportunístico ex-ante, enquadra-se na descrição deste pressuposto discutido por Williamson, citado em Zylbersztajn (1995), as inadimplências a que estiveram e ainda se encontram expostos parte dos produtores regionais, compõem estratégia de atuação elaborada por alguns agentes de comercialização para que as inadimplências aconteçam em período de tempo determinado e afetem em grupo os produtores. Nestes, os agentes assumem a figura de estelionatários; após o tempo necessário para construção de reputação, de forma articulada, deixam de honrar com a totalidade ou quase totalidade dos pagamentos dos cheques pré-datados emitidos para a aquisição dos lotes de uva.

O outro tipo de situação, o comportamento oportunístico induzido (ex-post), é parcialmente explicado pela aquisição de produtos de baixa qualidade, de frutas que, no linguajar popular, "não dão prateleira" e são decorrentes de sistemas produtivos menos tecnificados. Deixam a desejar na condução dos tratos culturais da videira ou nas aplicações preventivas de defensivos, apresentando portanto maior perecibilidade. As entrevistas com atacadistas revelaram que pode ocorrer de se comprarem uvas com boa aparência, mas que muitas vezes não suportam viagens aos centros consumidores de destino. Ao ver perdida sua carga, o agente de comercialização acaba por repassar a perda para $o$ produtor, que se vê desguarnecido.

Nas entrevistas, os produtores, quando solicitados que discorressem sobre as fontes de incertezas inerentes ao mercado e sobre as inadimplências a que eles próprios ou demais produtores regionais estiveram submetidos, não manifestaram associação entre risco de mercado e qualidade da fruta na origem, atribuindo as inadimplências dos compradores apenas a uma possível má-fé ou comportamento oportunístico destes. Nas entrevistas com os técnicos e distribuidores, foi possível inferir que os agentes de comercialização têm, na alta perecibilidade da fruta, a grande fonte de incerteza, a qual está intrinsecamente relacionada tanto com a tecnologia aplicada aos sistemas produtivos, quanto com os cuidados presentes na condução da cultura e no manuseio de colheita e pós-colheita.

Sobre os canais de comercialização mais utilizados, no passado, os produtores vendiam preferencialmente para representantes de empresas permissionárias dos entrepostos CEAGESP e CEASAs; atualmente, $90 \%$ dos produtores entrevistados vendem para representantes de distribuidores regionais que fazem visitas às propriedades. Apenas o produtor que desenvolveu selo próprio e alcançou boa reputação no mercado, permanece ofertando seu produto para atacadistas do entreposto terminal, o qual, pela especificidade de marca, consegue sistematicamente preço diferenciado pela sua fruta.

Indagados sobre as vantagens e desvantagens de realizarem as vendas para os agentes regionais, os produtores afirmaram que, embora as transações com entrepostos terminais sejam mais seguras, os custos que envolvem as transações tornam mais rentáveis as vendas para a primeira categoria de compradores. Os custos de comercialização com permissionários do entreposto CEAGESP somaram, na safra de 2005, em média, $34,5 \%$ da receita obtida por caixa de $7 \mathrm{~kg}$ e representam as despesas incorridas com frete, comissão do atacadista, impostos e descarga. Os custos de comercialização que envolvem as vendas para a outra categoria de compradores não foram explicitados, pois o preço que recebem pelo produto é posto na propriedade.

\section{O ambiente institucional}

O papel das instituições na sociedade é reduzir as incertezas ao estabelecer uma estrutura estável (mas não necessariamente eficiente) para a intervenção humana (North, citado por ZYLBERSZTAJN, 1995). Na região de Jales, além das instituições representantes do poder público local ou estadual, tem surgido alguma iniciativa de instituições de caráter formal ou informal decorrentes de relações de proximidade entre produtores rurais, agentes de comercialização e outros atores sociais, voltadas tanto para discutir estratégias de enfrentamento de restrições de mercado a que estão expostos os fruticultores, quanto para o delineamento de metas para a expansão do mercado regional de produção de frutas. Em 1999, surgiu o Instituto Brasileiro de Desenvolvimento, Pesquisas e Proteção ao meio Rural (IBDR), de iniciativa privada, que desenvolveu um trabalho voltado para discussão de atitudes preventivas que os fruticultores devem assumir para minimizar as incertezas associadas à comercialização. As recomendações encontram-se expressas na cartilha "os dez mandamentos do produtor rural contra o calote" (IBDR, 2000).

Em 2001, articulou-se ampla discussão com vistas à formação de um fórum envolvendo os diversos atores sociais dos segmentos público e privado atuantes nas cadeias produtivas de frutas, para o delineamento das ações necessárias visando a tornar mais dinâmico o pólo frutícola regional.

Na região em estudo, ainda não se pode dizer que arranjos institucionais baseados na organização coletiva de agricultores, como cooperativas e associações, tenham conseguido auferir sucesso na coordenação das transações econômicas entre níveis de mercado ou prestação de serviços na etapa de comercialização, contribuindo para a redução dos custos de transação. Em 2006, um novo arranjo foi proposto, trata-se do programa denominado "Barracão do Produtor", um projeto concebido pelo entreposto terminal CEAGESP com parceria da Cooperativa Jales que objetiva 
qualificar os produtores para melhor desenvolverem as funções de comercialização, bem como o desenvolvimento de uma marca da fruta produzida regionalmente, com certificação de qualidade.

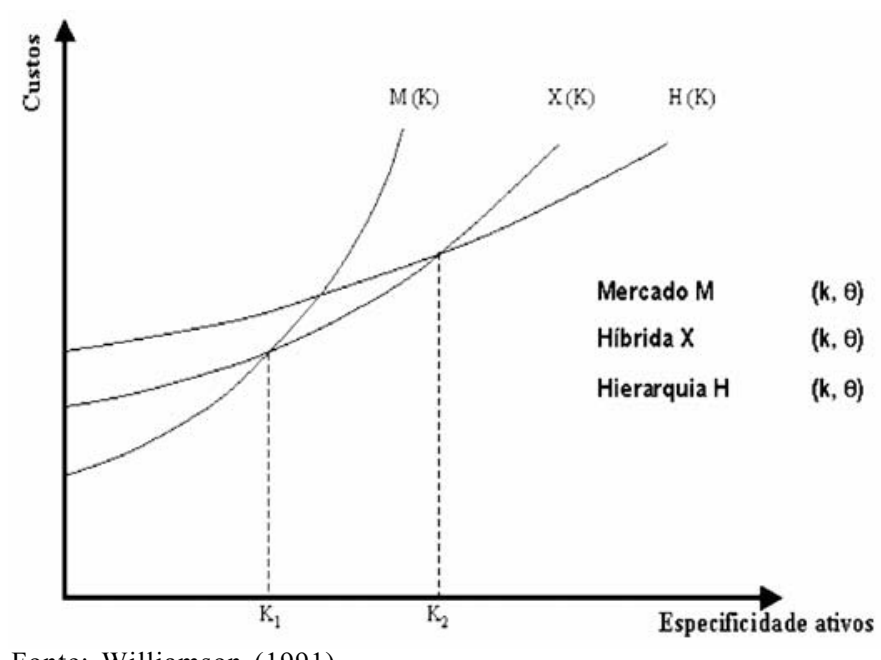

Fonte: Williamson (1991)

FIGURA 1 - Custos de cada estrutura de governança e a especificidade dos ativos.

\section{CONCLUSÕES}

1-A pesquisa permite concluir que os agentes de comercialização encarregados da distribuição das uvas finas para mesa, produzidas na região de Jales, apresentam diferentes níveis de especialização, os quais guardam correspondência com os níveis de especialização e tecnificação do segmento produtivo. Para produtores que produzem frutas de melhor qualidade, encontram-se transações que se distanciam da forma mercado e se aproximam mais de formas hierárquicas. Os produtores que não conseguem produzir frutas de qualidade, encontram-se mais sujeitos a efetivar vendas com distribuidores de menor especialização, além de se encontrarem mais expostos a ações oportunísticas de agentes de intermediação comercial.

2-Atores sociais locais têm implementado iniciativas pontuais de organização dos produtores objetivando atingir-se maior eficiência nas funções de comercialização. Embora tais programas não tenham logrado alcançar resultados concretos, se os atores da cadeia produtiva local avançarem no sentido das metas propostas, as relações de governança do tipo híbrida tenderão a tornar-se mais freqüentes, resultando em maior segurança para os produtores.

\section{REFERÊNCIAS}

ALMEIDA, G.V.B. Embalagem e comercialização de uvas. In: SIMPÓSIO BRASILEIRO SOBRE UVAS DE MESA, 1., 2000, Ilha Solteira. Anais.. lha Solteira: Unesp/FEIS, 2000. p.218-39.

BELIK, W., NURIA, A. C. Formas Híbridas de Coordenação na Distribuição de Frutas, Legumes e Verduras no Brasil. Disponível em: $<$ http://www.eco.unicamp.br/artigos/artigo173.htm $>$. Acesso em: 20 jan. 2006.

COASE, R. H. The nature of the firm. Econômica, London, v.14, n.16, p.371-85, 1937.

COSTA, G.C; REIS, J.N.P; OLIVEIRA, J.E.C; MAYORGA, R.D. Análise das estruturas de governança: o caso da produção e comercialização de melão em áreas de assentamento no Rio Grande do Norte. In: CONGRESSO BRASILEIRO DEECONOMIA E SOCIOLOGIA RURAL, 41., 2003. Passo Fundo. Anais... Passo Fundo: SOBER, 2003.p.87.

FARINA, E. M. M. Q.; AZEVEDO, P. F. de; SAES, M. S. M. Competitividade: mercado, estado e organizações. São Paulo: Singular, 1997.287p.

FAULIN, E.J.; AZEVEDO, P.F. Distribuição de frutas, legumes e verduras na agricultura familiar: uma análise das transações. In: CONGRESSO BRASILEIRO DE ECONOMIA E SOCIOLOGIA RURAL, 41., 2003. Passo Fundo. Anais... Passo Fundo: SOBER, 2003.p.51.

GONÇALVES, J. S.;AMARO, A.A.; MAIA, M.L.;SOUZA, S.A.M. e PEREZ, L.H. Frutas. Prognóstico Agrícola, São Paulo, v.2, p. 209-11, 1998.

GUTIERREZ, A.S.D.; RESENDE, J.V. A automação dos supermercados e a classificação de produtos hortifrutícolas. Informações Econômicas, São Paulo, v. 30, p. 39- 43, jan. 2000.

IBDR- SIPC-RURAL. Os dez mandamentos do produtor rural contra o calote. Jales-SP, 2000. 31p.

SATO , G.S. Análise do consumo de uva para mesa no Brasil. Informações Econômicas, São Paulo, v.34, n.7, p.50.53, jul.2004

TARSITANO, M.A.A. Avaliação econômica da cultura da videira na região de Jales-SP. 2001. 121 f. Tese (Livre-Docência) Faculdade de Engenharia, Universidade Estadual Paulista "Júlio de Mesquita Filho, Universidade Estadual Paulista, Ilha Solteira, 2001.

WILLIAMSON, O. E. The economic institutions of capitalism. London: Free Press, 1985.

WILLIAMSON, O. E. Comparative economic organization: the analysis of discrete structural a1ternatives. Administrative Science Quarterly, Ithaca, n. 36, p. 269-96, 1991.

ZYLBERSTAJN, D Estruturas de governança e coordenação do agribusiness: uma aplicação da Nova Economia das Instituições. 1995. 237 f. Tese (Livre-Docência). Faculdade de Economia, Administração e Contabilidade/Departamento de Administração,Universidade de São Paulo, São Paulo, 1995. 